\title{
In Vitro and In Vivo Antileishmanial Activities of Pistacia vera Essential Oil
}

\author{
Authors \\ Hossein Mahmoudvand ${ }^{1,2}$, Ebrahim Saedi Dezaki ${ }^{3}$, Behrouz Ezatpour ${ }^{1}$, Iraj Sharifi ${ }^{3}$, Farnaz Kheirandish ${ }^{2}$, \\ Marzieh Rashidipour ${ }^{4}$ \\ Affiliations \\ ${ }^{1}$ Razi Herbal Medicines Research Center, Lorestan University of Medical Sciences, Khorramabad, Iran \\ 2 Department of Medical Parasitology and Mycology, Lorestan University of Medical Sciences, Khorramabad, Iran \\ ${ }^{3}$ Leishmaniasis Research Center, Kerman University of Medical Sciences, Kerman, Iran \\ ${ }^{4}$ Young Researchers and Elite Club, Islamic Azad University, Khorramabad Branch, Khorramabad, Iran
}

Key words

- Pistacia vera

- Anacardiaceae

- essential oil

- cutaneous leishmaniasis

received

revised

October 23, 2014

accepted

Sept. 29, 2015

Bibliography

Dol http://dx.doi.org/

10.1055/s-0035-1558209

Published online February 1 ,

2016

Planta Med 2016; 82: 279-284

(C) Georg Thieme Verlag KG

Stuttgart · New York .

ISSN 0032-0943

\section{Correspondence}

Dr. Behrouz Ezatpour, PhD

Razi Herbal Medicines

Research Center

Lorestan University

of Medical Sciences

Khorramabad

Iran

Phone: + 986633204005

Fax: + 986633204005

bezatpour@gmail.com

\section{Abstract}

\section{$\nabla$}

This study aims to evaluate the in vitro and in vivo antileishmanial activities of Pistacia vera essential oil and compare their efficacy with a reference drug, meglumine antimoniate (Glucantime ${ }^{\circledR}$ ). This essential oil $(0-100 \mu \mathrm{g} / \mathrm{mL})$ was evaluated in vitro against the intracellular amastigote forms of Leishmania tropica (MHOM/IR/2002/Mash2) and then tested on cutaneous leishmaniasis of male BALB/c mice by Leishmania major (MRHO/IR/75/ $\mathrm{ER})$. In the in vitro assay, it could be observed that $P$. vera essential oil significantly $(\mathrm{p}<0.05)$ inhibited the growth rate of amastigote forms $\left(\mathrm{IC}_{50}\right.$ of $21.3 \pm 2.1 \mu \mathrm{g} / \mathrm{mL}$ ) in a dose-dependent response compared with the control drug. Meglumine antimoniate also demonstrated antileishmanial effects with an $\mathrm{IC}_{50}$ value of $44.6 \pm 2.5 \mu \mathrm{g} / \mathrm{mL}$ for this clinical stage. In the in vivo assay, the results indicated that $30 \mathrm{mg} / \mathrm{mL}$ of the essential oil had potent suppression effects on cutaneous leishmaniasis in BALB/c mice (87.5\% recovery), while 10

\section{Introduction}

$\nabla$

Cutaneous leishmaniasis (CL) is a protozoan infection caused by protozoa of the genus Leishmania. This disease is characterized by chronic skin lesions and leaves permanent scars as the deformation of the infected area [1]. CL is a public health problem at a global level affecting 1.5 million people annually worldwide [1]. In Iran, the principal pathogenic species of CL are Leishmania tropica and Leishmania major [2]. The current first-line chemotherapy of leishmaniasis with antimonial drugs such as meglumine antimoniate and sodium stibogluconate is a challenge due to having the problems of emerging resistance, severe side effects, or high costs [3]. Moreover, the secondline drugs have some limitations for use because of the prolonged length of therapy as well as ad- and $20 \mathrm{mg} / \mathrm{mL}$ of the essential oil represented the suppression effects as weak to intermediate. The mean diameter of the lesions decreased about 0.11 and $0.27 \mathrm{~cm}$ after the treatment of the subgroups with the essential oil concentrations of 10 and $20 \mathrm{mg} / \mathrm{mL}$, respectively. In contrast, in the subgroup treated with the essential oil concentration of $30 \mathrm{mg} / \mathrm{mL}$, the mean diameter of the lesions decreased about $0.56 \mathrm{~cm}$. In the control subgroups, the mean diameter of the lesions increased to $1.01 \mathrm{~cm}$. The main components of $P$. vera essential oil were limonene (26.21\%), $\alpha$-pinene (18.07\%), and $\alpha$-thujene (9.31\%). It was also found that $P$. vera essential oil had no significant cytotoxic effect on J774 cells. The present study found that $P$. vera essential oil showed considerable in vitro and in vivo effectiveness against $L$. tropica and $L$. major compared to the reference drug. These findings also provided the scientific evidence that natural plants could be used in traditional medicine for the prevention and treatment of cutaneous leishmaniasis.

verse reactions [4]. Since vaccines are not yet available for $\mathrm{CL}$, the maintenance and improvement of the existing treatment regimens and discovery initiatives have been found to be the only ways of controlling this important tropical disease [5]. For decades plant extracts and plant-derived compounds, due to having few side effects, low cost, and high availability, have been valuable sources that are commonly used to treat a wide range of disease conditions including infectious diseases [6]. The genus Pistacia belongs to the family Anacardiaceae. Among the 15 known species of pistachios, only three species grow in Iran, which include Pistacia vera L., Pistacia khinjuk Stocks ex Stocks, and Pistacia atlantica Desf. [7]. $P$. vera is the only species of the genus cultivated commercially and the rest of the species are mostly used as rootstocks for $P$. vera [8]. In folk 
Table 1 Essential oil composition of $P$. vera identified by GC/MS.

\begin{tabular}{|c|c|c|c|}
\hline No & Components & $\mathbf{R} \mathbf{l}^{\mathbf{a}}$ & $\begin{array}{l}\text { \% Compo- } \\
\text { sition }\end{array}$ \\
\hline 1. & Tricyclene & 956 & 1.24 \\
\hline 2. & $\alpha$-Thujene & 973 & 9.3 \\
\hline 3. & $\alpha$-Pinene & 987 & 18.1 \\
\hline 4. & Camphene & 993 & 4.4 \\
\hline 5. & Sabinene & 1017 & 0.6 \\
\hline 6. & $\beta$-Pinene & 1026 & 3.1 \\
\hline 7. & $\beta$-Myrcene & 1031 & 1.9 \\
\hline 8. & $\alpha$-Terpinene & 1035 & 1.6 \\
\hline 9. & $\Delta$-2-Carene & 1060 & 2.8 \\
\hline 10. & p-Cymene & 1072 & 0.7 \\
\hline 11. & Limonene & 1097 & 26.2 \\
\hline 12. & $y$-Terpinene & 1101 & 2.1 \\
\hline 13. & $\alpha$-Terpinolene & 1179 & 9.3 \\
\hline 14. & 1,8-Menthadien-5-ol & 1184 & 1.1 \\
\hline 15. & 3-Cyclohexen & 1196 & 1.3 \\
\hline 16. & $\alpha$-Terpineol & 1199 & 0.6 \\
\hline 17. & Borneol & 1234 & 7.5 \\
\hline 18. & Thujopsene & 1288 & 0.4 \\
\hline 19. & $\beta$-Himachalene & 1297 & 0.7 \\
\hline 20. & Cembrene & 1354 & 0.9 \\
\hline 21. & E-Caryophyllene & 1428 & 2.1 \\
\hline 22. & Bis(2-ethylhexyl) phthalate & 1448 & 0.6 \\
\hline 23. & 1,13-Teridecadiene & 1498 & 0.6 \\
\hline 24. & delta-Cadinene & 1581 & 0.6 \\
\hline \multirow[t]{2}{*}{25.} & Cyclohexadecane & 1587 & 0.25 \\
\hline & Total & & 97.93 \\
\hline
\end{tabular}

a Retention indices on nonpolar DB-5 ms column in reference to $n$-alkanes

medicine, different parts of $P$. vera including resin, leave, fruit, and aerial parts are traditionally used for analgesic, carminative, astringent, stomachic, aphrodisiac, antitussive, diuretic, and expectorant purposes [7]. Reviews have also reported that $P$. vera has various biological activities such as anti-inflammatory, antinociceptive, antiatherogenic, and hypoglycemic ones [9-11]. Moreover, in several studies, antibacterial, antiviral, antifungal, and antiparasitic activities of this plant against several pathogenic strains have been proven $[12,13]$. The major chemical constituents of $P$. vera essential oil are hydrocarbon and oxygenated monoterpens such as $\alpha$-pinene [14]. However, some factors such as plant species and part, cultivar sex, geographical origin, harvesting time, and climatic conditions could affect the chemical composition and functional activity of this plant [15]. The present study aimed to evaluate the chemical composition of $P$. vera essential oil and investigate its antileishmanial activities against $L$. tropica and L. major in in vitro and in vitro models, respectively.

\section{Results \\ $\nabla$}

- Table 1 shows the results obtained by gas chromatography/ mass spectrometry (GC/MS) analysis of $P$. vera essential oil. Twenty-five compounds were identified, which represented $97.9 \%$ of the total oil. The main components were limonene (26.2\%), $\alpha$-pinene (18.1\%), $\alpha$-thujene (9.3\%), and $\alpha$-terpinolene (9.3\%).

The findings demonstrated that $P$. vera essential oil inhibited the growth rate of intramacrophage amastigotes of $L$. tropica as a dose-dependent response. The obtained $\mathrm{IC}_{50}$ values were $21.3 \pm$
Table 2 The IC50 and CC50 values and SI determined for $P$. vera essential oil and for meglumine antimoniate. The antileishmanial activity was determined against intracellular amastigotes of $L$. tropica; the cytotoxicity was determined on $\mathbf{j 7 7 7 4}$ cells.

\begin{tabular}{|l|lll|}
\hline SI & $\begin{array}{c}\mathbf{C C}_{50}(\boldsymbol{\mu g} / \mathrm{mL}) \text { on } \\
\mathbf{J 7 7 4} \text { cells }( \pm \text { SD) }\end{array}$ & $\begin{array}{l}\mathbf{I C}_{50}(\boldsymbol{\mu g} / \mathrm{mL}) \text { on } \\
\text { amastigotes }( \pm \text { SD) }\end{array}$ & $\begin{array}{l}\text { Tested } \\
\text { material }\end{array}$ \\
\hline 10.1 & $216.3 \pm 8.15$ & $21.3 \pm 2.1$ & Essential oil \\
\hline 27.5 & $1225.6 \pm 11.1$ & $44.6 \pm 2.5$ & $\begin{array}{l}\text { Meglumine } \\
\text { antimoniate }\end{array}$ \\
\hline
\end{tabular}

${ }^{a} C_{50}$ for $] 774$ cells $/ I_{50}$ for amastigote forms of $L$. tropica

Table 3 Inhibition of the infection in macrophage cells after treatment of $L$. tropica promastigotes with $P$. vera essential oil. Data are expressed as the mean \pm SD $(n=3)$.

\begin{tabular}{|lll|}
$\begin{array}{l}\text { Infectiveness } \\
\text { reduction }\end{array}$ & $\begin{array}{l}\text { Percentage of infected } \\
\text { macrophages }\end{array}$ & Promastigotes \\
- & $84.1 \pm 3.5$ & Non-treated \\
\hline $77 \pm 3.1$ & $19.3 \pm 1.2$ & $\begin{array}{l}\text { Treated with essential } \\
\text { oil }(5 \mu \mathrm{g} / \mathrm{mL})\end{array}$ \\
\hline
\end{tabular}

Table 4 Comparison of NO production in macrophage cells after treatment with various concentrations of $P$. vera essential oil.

\begin{tabular}{|c|c|}
\hline Production of nitric oxide (nM) & Concentration \\
\hline 16 & 3.125 \\
\hline 9.3 & 6.25 \\
\hline 6 & 12.5 \\
\hline 11 & Non-treated \\
\hline
\end{tabular}

2.05 and $44.6 \pm 2.5 \mu \mathrm{g} / \mathrm{mL}$ for the $P$. vera essential oil and meglumine antimoniate, respectively ( Table 2 ). The findings demonstrated that the promastigote forms of $L$. tropica with no drugs were able to infect $84.1 \%$ of the macrophage cells, while promastigotes treated with $P$. vera essential oil had a potency to infect only $19.3 \%$ of the macrophages cells ( Table 3 ). These results indicate that the infectivity of promastigotes of $L$. tropica is significantly $(\mathrm{p}<0.05)$ reduced after incubation with $P$. vera essential oil. The findings also exhibited that the essential oil of $P$. vera triggered the production of $16 \mu \mathrm{M}$ of nitric oxide (NO) at the low concentration of $3.125 \mu \mathrm{g} / \mathrm{mL}$ compared to $11 \mu \mathrm{M}$ for the untreated macrophages. In contrast, the essential oil at a higher concentration $(\geq 6.25 \mu \mathrm{g} / \mathrm{mL})$ reduced the production of NO to $6 \mu \mathrm{M}$ compared to the untreated macrophages ( $\bigcirc$ Table 4 ). Moreover, the in vitro assay demonstrated that $P$. vera essential oil had no significant cytotoxicity in J774 cells. The cytotoxic concentration for $50 \%$ of the cells $\left(\mathrm{CC}_{50}\right)$ value of the essential oil was $216.3 \pm$ $8.15 \mu \mathrm{g} / \mathrm{mL}$. In addition, the selectivity index (SI) of greater than 10 for $P$. vera essential oil represented its safety to the macrophages and specificity to the parasite ( Table 2 ).

The findings demonstrated that in the infected mice treated with $30 \mathrm{mg} / \mathrm{mL}$ of $P$. vera essential oil, the number of parasites was significantly $(\mathrm{p}<0.05)$ decreased compared to the untreated mice, while 10 and $20 \mathrm{mg} / \mathrm{mL}$ of the essential oil reduced the number of parasites in a dose-dependent manner ( $\bullet$ Fig. 1 ). The untreated group did not show any decrease in the number of parasites. After 30 days of treatment, $87.5 \%$ recovery (seven cases) was observed in the cases treated with $30 \mathrm{mg} / \mathrm{mL}$ essential oil, 


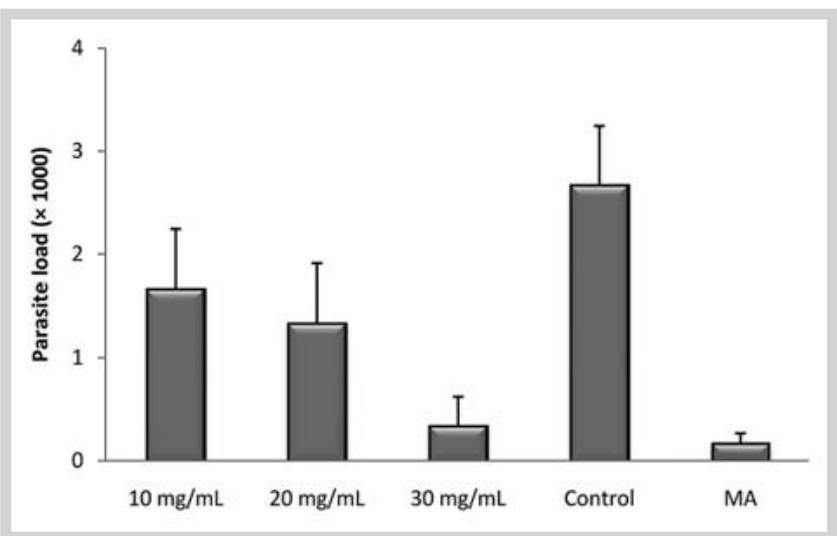

Fig. 1 Comparison of mean number of parasites (parasite load) in infected mice after treatment with various concentrations of $P$. vera essential oil.

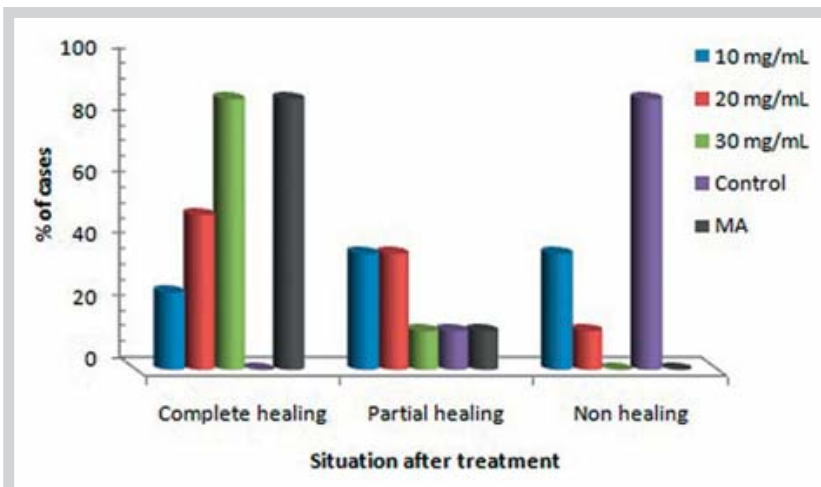

Fig. 2 Comparison of the healing rate of lesions in infected mice after treatment with various concentrations of $P$. vera essential oil. (Color figure available online only.)

whereas with 10 and $20 \mathrm{mg} / \mathrm{mL}$ of $P$. vera essential oil, 25 and $50 \%$ recovery was observed, respectively ( $\boldsymbol{O}$ Fig. 2 ). The mean diameter of the lesions decreased by 0.11 and $0.27 \mathrm{~cm}$ after the treatment of the groups with concentrations of 10 and $20 \mathrm{mg} / \mathrm{mL}$ of $P$. vera essential oil, respectively. In the group treated with $P$. vera essential oil at the concentration of $30 \mathrm{mg} / \mathrm{mL}$, the mean diameter of the lesions decreased by $0.56 \mathrm{~cm}$, while in the untreated group, the mean diameter of the lesions increased by $1.01 \mathrm{~cm}$ (OTable 5).

\section{Discussion}

$\nabla$

Natural products, either as pure compounds or as standardized extracts, provide unlimited opportunities for new drug discoveries because of the unmatched availability of chemical diversity [16]. According to the World Health Organization (WHO), more than $80 \%$ of the world's population relies on traditional medicine for their primary health care needs. In the past decades, the advent of synthetic antimicrobial drugs has caused reluctance in plants as a rich resource of antimicrobial agents [17]. However, in recent years, the emergence of some limitations in the use of these drugs has caused changes in the situation of and interest in the field of ethnobotanical research [18]. In this study, the in vitro and in vivo antileishmanial effects of $P$. vera essential oil against $L$. tropica and $L$. major were investigated. In the in vitro assay, $P$. vera essential oil significantly reduced the mean infection rate and subsequently the viability of amastigote forms of $L$. tropica in the macrophages. In line with the present work, Orhan et al. [12] reported that $P$. vera branch extract with a $4.8 \mu \mathrm{g} / \mathrm{mL}$ concentration significantly inhibited (77.3\%) the growth of $L$. donovani, whereas the dry leaf extract (PV-DL) was active against Plasmodium falciparum (60.6\% inhibition). They also indicated that the $\mathrm{IC}_{50}$ values of these extracts were $2.3 \mu \mathrm{g} / \mathrm{mL}$ for the amastigotes of $L$. donovani grown in axenic culture and $3.65 \mu \mathrm{g} /$ $\mathrm{mL}$ for P. falciparum [12]. Of course, it should be noted that this difference in susceptibility of amastigote stages between the present study and the study conducted by Orhan et al. [12] might be due to the use of extracellular amastigotes of $L$. donovani grown in axenic culture, while in this investigation we used intramacrophage amastigotes.

In the in vivo assay, the results demonstrated that $30 \mathrm{mg} / \mathrm{mL}$ of the essential oil had potent suppression effects on the $\mathrm{CL}$ in male BALB/c mice infected with $L$. major (87.5\% recovery), while 10 and $20 \mathrm{mg} / \mathrm{mL}$ resulted in a weak and moderate suppression, respectively. Since NO produced in macrophages plays a pivotal role as a leishmanicidal agent, in this survey we evaluated NO production in macrophages exposed to various concentrations of $P$. vera essential oil. The results obtained showed that the essential oil of $P$. vera triggered the production of $\mathrm{NO}$ at the low concentration, but in higher concentrations, it reduced the production of NO compared to the untreated macrophages.

The phytochemical screening of $P$. vera essential oil showed the presence of terpenoids, phenols, and flavonoids in this plant [7]. Furthermore, the chemical composition of $P$. vera essential oil using GC/MS revealed that the main components were limonene (26.21\%), $\alpha$-pinene (18.07\%), $\alpha$-thujene (9.31\%), and $\alpha$-terpinolene (9.28\%). Therefore, the plant analyzed in this research was a new chemotype of $P$. vera. It has been previously proven that the chemical composition of essential oils depends on species, climate, collection time, and growth stage, altering the studied biological activities [15].

So far, individual activities of these compounds have been demonstrated [17]. Furthermore, in various studies, potent antileishmanial activities of these compounds, such as terpenic derivates, carvacrol, $p$-cymene, thymol, carvone, limonene, and terpinene, have been demonstrated [19-22]. Therefore, phytoconstituents in these plants could be responsible for their antileishmanial activity although their exact mode of action is poorly understood. However, in the case of the antimicrobial mechanism of some terpenoid compounds such as monoterpens, the main component of P. vera, Sikkema et al. [23] revealed that they are diffused into pathogens and damage cell membrane structures. On the other hand, other reports have suggested that the antimicrobial activity is related to the ability of terpenes in affecting not only permeability but also other functions of cell membranes; these compounds might cross the cell membranes, penetrate into the interior of the cell, and interact with critical intracellular sites [24, 25].

In the case of cytotoxic effects, it was found that $P$. vera essential oil had no cytotoxic effects on J774 cells. The SI value $\geq 10$ of the essential oil showed its safety to the macrophages and specificity to parasites [26]. Similar to the present findings, Orhan et al. [12] showed that $P$. vera extract did not exert any cytotoxic effect on mammalian L6 cells, even at very high concentrations. Therefore, 


\begin{tabular}{|c|c|c|c|c|}
\hline p value & $\begin{array}{l}\text { Size of lesions }(\mathrm{cm}) \text { after } \\
\text { treatment ( } 30 \text { days) ( } \pm \text { SD) }\end{array}$ & $\begin{array}{l}\text { Size of lesions }(\mathrm{cm}) \\
\text { before treatment }( \pm S D)\end{array}$ & $\begin{array}{l}\text { Concentra- } \\
\text { tions }(\mathrm{mg} / \mathrm{mL})\end{array}$ & \\
\hline$<0.05$ & $1.16 \pm 0.3$ & $1.27 \pm 0.3$ & 10 & \\
\hline$<0.05$ & $1.04 \pm 0.2$ & $1.31 \pm 0.3$ & 20 & Essential oil \\
\hline$<0.05$ & $0.77 \pm 0.2$ & $1.33 \pm 0.3$ & 30 & \\
\hline$<0.05$ & $0.42 \pm 0.1$ & $1.37 \pm 0.2$ & 30 & $\begin{array}{l}\text { Meglumine } \\
\text { antimoniate }\end{array}$ \\
\hline- & $2.40 \pm 0.2$ & $1.39 \pm 0.25$ & - & Control \\
\hline
\end{tabular}

Table 5 Effects of $P$. vera essential oil on the size of lesions in BALB/C mice infected by $L$. major. it can be suggested that $P$. vera essential oil is safe for mammalian cells.

To conclude, the present study found that $P$. vera essential oil showed in vitro and in vivo effectiveness against $L$. tropica and L. major, respectively. The findings of this study also provide scientific evidence that natural plants could be used in traditional medicine for the prevention and treatment of $\mathrm{CL}$.

\section{Materials and Methods \\ $\nabla$}

\section{Chemicals}

Meglumine antimoniate (Glucantime ${ }^{\circledR}, 99 \%$ purity), used as the control drug $(1.5 \mathrm{~g} / 5 \mathrm{~mL})$ of antileishmanial activity, was purchased from Aventis. Penicillin and streptomycin were obtained from Alborz Pharmacy and were stored at room temperature $\left(25^{\circ} \mathrm{C}\right)$ until testing. MTT powder [3-(4.5-dimethylthiazol-2-yl)2.5-diphenyl tetrazolium bromide)], fetal calf serum (FCS), RPMI-1640 medium with L-glutamine, and Griess reagent (A and B) were purchased from Sigma-Aldrich. All of the other chemicals and solvents used were of the highest purity commercially available.

\section{Collection of plant materials}

The plant materials (branch) were collected from rural regions of Kerman province, south east of Iran, from May to September 2013. They were identified by a botanist (Dr. Sharififar) of the Botany Department of Shahid Bahonar University, Kerman, Iran. A voucher specimen of the plant materials was deposited at the Herbarium of Department of Pharmacognosy of School of Pharmacy, Kerman University of Medical Science, Iran (KF 1136). The collection of plant materials in this study was carried out on private land, and no specific permissions were required for this location. In addition, we confirmed that the present field study did not involve endangered or protected species.

\section{Isolation of essential oil}

One hundred g of powdered plant materials (branch) were subjected to hydrodistillation for $3 \mathrm{~h}$ using an all-glass clevengertype apparatus. The essential oil obtained was dried over anhydrous sodium sulfate and stored in darkness at $4{ }^{\circ} \mathrm{C}$ in airtight glass vials closed under nitrogen gas until testing [27].

\section{Drug dilutions}

To prepare the dilutions of the $P$. vera essential oil, $0.1 \mathrm{~mL}$ of the essential oil was dissolved in $0.97 \mathrm{~mL}$ of normal saline. In addition, to enhance the dispersal of the essential oil in normal saline, $0.03 \mathrm{~mL}$ of Tween 20 was added to the test tube. The resulting solution was mixed adequately by a magnetic stirrer. Serial dilutions were carried out to obtain the essential oil at concentrations of 3.125 to $100 \mu \mathrm{g} / \mathrm{mL}$. The selection of dilutions of $P$. vera essential oil were based on initial experiments, which also showed that normal saline plus Tween 20 did not cause an effect on the growth of parasites.

\section{Gas chromatography/mass spectrometry analysis of essential oil}

In this study, GC analysis was carried out by a Hewlett-Packard 6890 with an HP-5MS column $(30 \mathrm{~mm} \times 0.25 \mathrm{~mm}$, film thickness $0.25 \mathrm{~mm}$ ). The column temperature was maintained at $55^{\circ} \mathrm{C}$ for $3 \mathrm{~min}$ and programmed to $180^{\circ} \mathrm{C}$ at a rate of $5^{\circ} \mathrm{C}$ per min, and kept constant at $220^{\circ} \mathrm{C}$ for $5 \mathrm{~min}$. Injector and interface temperatures were $220^{\circ} \mathrm{C}$ and $290^{\circ} \mathrm{C}$, respectively. The flow rate of helium as a carrier gas was $1 \mathrm{~mL} / \mathrm{min}$ C. F. The percentages were calculated by electronic integration of FID peak areas without the use of response factors correction. Linear retention indices for all components were determined by coinjection of the samples with a solution containing a homologous series of C8-C22 n-alkanes. GC/MS analysis was performed using a Thermoquest-Finnigan gas chromatograph equipped with fused silica capillary DB-5 column ( $30 \mathrm{~mm} \times 0.25 \mathrm{~mm}$, film thickness $0.25 \mathrm{~mm}$ ) coupled with a TRACE mass. Helium was used as a carrier gas with an ionization voltage of $70 \mathrm{eV}$. Ion source and interface temperatures were $220^{\circ} \mathrm{C}$ and $290^{\circ} \mathrm{C}$, respectively. The mass range was from 40 to $400 \mathrm{u}$. The oven temperature program was the same as above for the GC.

\section{Identification of the essential oil components}

The components of the essential oil were identified by comparison of their retention indices and mass spectra with those of the standards of the Wiley 2001 library data of the GC/MS system or with those reported in the literature [28].

\section{Parasite and cell culture}

Reference strains of $L$. tropica (MHOM/IR/2002/Mash2) and $L$. major (MRHO/IR/75/ER) were kindly provided by the Center for Research and Training in Skin Diseases and Leprosy (Tehran, Iran). The parasites were cultured in NNN medium and subcultured in RPMI 1640 supplemented with penicillin $(200 \mathrm{IU} / \mathrm{mL})$, streptomycin $(100 \mu \mathrm{g} / \mathrm{mL})$, and $15 \%$ heat-inactivated FCS. The murine macrophage cell line (J774-A1) was obtained from the Pasteur Institute of Iran (Tehran, Iran). The cells were cultured and maintained in Dulbecco's modified Eagle's medium (DMEM) supplemented with $10 \% \mathrm{FBS}$ at $37^{\circ} \mathrm{C}$ in $5 \% \mathrm{CO}_{2}$.

\section{In vitro antileishmanial activity}

Anti-amastigote assay: The intracellular amastigote assay with the $P$. vera essential oil was carried out according to the method described elsewhere [29]. Briefly, before adding the macrophages to the plates, $1 \mathrm{~cm}^{2}$ cover slips were placed in the wells of 6 chamber slides (Lab-Tek, Nalge Nunc International). In the next step, $200 \mu \mathrm{L}$ of macrophage cells $\left(10^{5} / \mathrm{mL}\right)$ were incubated at $37^{\circ}$ 
$\mathrm{C}$ in $5 \% \mathrm{CO}_{2}$ for $2 \mathrm{~h}$ in DMEM. Then, $200 \mathrm{uL}$ of $L$. tropica promastigotes $\left(10^{6} / \mathrm{mL}\right)$ in the stationary phase were added to the murine macrophages so that proportion of Leishmania/macrophage was 10:1 and were incubated again in a similar condition for $24 \mathrm{~h}$. Free parasites were removed by washing with RPMI 1640 medium and the infected macrophages were treated with $50 \mu \mathrm{L}$ of various concentrations of essential oil $(0-100 \mu \mathrm{g} / \mathrm{mL})$ at $37^{\circ} \mathrm{C}$ in $5 \% \mathrm{CO}_{2}$ for $72 \mathrm{~h}$. At the end, the dried slides were fixed with methanol, stained by Giemsa, and observed under a light microscope. Also, the macrophages containing amastigotes without extract and those with no parasite and extract were considered positive and negative controls, respectively. Activity of the essential oil on intracellular amastigotes was evaluated by counting the number of amastigotes in each macrophage by examining 100 macrophages in comparison with those obtained with the positive control. The $50 \%$ inhibitory concentrations ( $\mathrm{IC}_{50}$ values) were measured for all of the tested drugs by the Probit test in SPSS software. All of the tests were performed in triplicate.

Inhibition of infection in macrophage cells: To determine the inhibitory effect of $P$. vera essential oil against the promastigote invasion of macrophages, promastigotes of L. tropica $\left(10^{6} / \mathrm{mL}\right)$ were preincubated in essential oil $(5 \mu \mathrm{g} / \mathrm{mL})$ for $2 \mathrm{~h}$ at room temperature (the selection of $5 \mu \mathrm{g} / \mathrm{mL}$ was based on the initial experiments which showed no significant effect on viability of promastigote cells). Then, promastigotes were washed with RPMI-1640 medium and incubated with murine macrophages (J774 cells) for $4 \mathrm{~h}$. After washing the cells again, the macrophages were stained by Giemsa and studied by a light microscope to evaluate the frequency of infection by counting 100 macrophages [30]. All of the tests were performed in triplicate.

Nitric oxide production determination: NO release in the supernatants of the macrophage culture was measured by the Griess reaction for nitrites. The supernatants $(100 \mu \mathrm{L})$ were collected $72 \mathrm{~h}$ after introducing the $P$. vera essential oil into the culture medium. The assay was done in triplicate wells in a 96-well tissue culture plate. To this, $60 \mu \mathrm{L}$ of Griess reagent A and then $60 \mu \mathrm{L}$ of Griess reagent $B$ were added. The plates were read at $540 \mathrm{~nm}$ in an ELISA plate reader (BioTek-ELX800).

Cytotoxic effects: Cytotoxicity effects of $P$. vera essential oil against J774-A1 cells were evaluated by cultivating macrophages $(5 \times$ $10^{5}$ ) with various concentrations of essential oil ( 0 to $\left.500 \mu \mathrm{g} / \mathrm{mL}\right)$ in 96 -well tissue culture plates at $37^{\circ} \mathrm{C}$ in $5 \% \mathrm{CO}_{2}$ for $48 \mathrm{~h}$. Cell viability was determined by the colorimetric MTT assay and the results are displayed as the percentage of dead cells compared to non-treated macrophages (100\% of viability). Moreover, $\mathrm{CC}_{50}$ was calculated by the Probit test in SPSS software [31].

Selectivity index: SI, calculated based on the equation of $\mathrm{CC}_{50}$ for murine macrophage cells $/ \mathrm{IC}_{50}$ for amastigote forms of $L$. tropica, was used to compare toxicity and activity of $P$. vera essential oil as described by Weniger et al. [26].

\section{In vivo antileishmanial activity}

Ethical statement: This study was carried out in strict accordance with the recommendations of the Guide for Care and Use of Laboratory Animals of National Institutes of Health. The protocol was approved by the Committee on Ethics of Animal Experiments, Lorestan University of Medical Sciences (Permit number: 91/27, 2013).

Animals: Forty male BALB/c mice (6-8 weeks old) were obtained from the Animal Breeding Stock Facility, Razi Institute of Iran (Karaj, Iran). They were housed in a colony room with a 12-h/ 12-h light/dark cycle at $21 \pm 2^{\circ} \mathrm{C}$ and handled according to the standard protocols for the use of laboratory animals [32].

Induction of cutaneous leishmaniasis in BALB/c mice: In this study, male BALB/c mice were infected subcutaneously with $0.1 \mathrm{~mL}$ of promastigotes of $L$. major $\left(2 \times 10^{6}\right.$ cells $\left./ \mathrm{mL}\right)$ harvested from the stationary phase at the base of the tail [33]. The mice were randomly divided into five groups and each group contained eight mice.

Treatment of infected mice: The infected mice were treated after 5 weeks when leishmanial lesions appeared. At first, the diameter of the lesions was measured before the treatment. Then, the lotion of essential oil with concentrations of 10,20 , and $30 \mathrm{mg} / \mathrm{mL}$ was applied by rubbing to each tested group on a daily basis for 30 days. The positive control group received meglumine antimoniate $(30 \mathrm{mg} / \mathrm{kg})$ as an intralesional injection. Before and after the treatment, the diameter of the lesions was measured (lesion borders) using a vernier caliperand to determine the number of parasites. Impression smears were prepared from the lesions, dried in air, fixed by methanol, and stained with Giemsa to specify the load of parasites by light microscopy [34].

\section{Statistical analysis}

Data analysis was carried out using SPSS statistical package version 17.0 (SPSS, Inc.). Differences between the test and control groups were analyzed by a t-test. In addition, $\mathrm{p}<0.05$ was considered statistically significant.

\section{Acknowledgments}

We would like to thank Ms. Ezzatkhah for cultivation of the parasites.

\section{Conflict of Interest}

$\nabla$

The authors declare no conflict of interest

\section{References}

1 World Health Organization. Control of the leishmaniasis. Geneva: WHO (Technical Report Series) 2010; 949: 5-12

2 Mahmoudvand H, Shakibaie M, Tavakoli R, Jahanbakhsh S, Sharifi I. In vitro study of leishmanicidal activity of biogenic selenium nanoparticles against Iranian isolate of sensitive and glucan-time-resistant Leishmania tropica. Iran J Parasitol 2014; 9: 452-460

3 Santos DO, Coutinho CE, Madeira MF, Bottino CG, Vieira RT, Nascimento $S B$. Leishmaniasis treatment - a challenge that remains: a review. Parasitol Res 2004; 103: 1-10

4 Croft SL, Sundar S, Fairlamb AH. Drug resistance in leishmaniasis. Clin Microbiol Rev 2006; 19: 11-26

5 Berman J. Clinical status of agents being developed for leishmaniasis. Expert Opin Investig Drugs 2005; 14: 1337-1346

6 Rocha LG, Almeida JR, Macedo RO, Barbosa-Filho JM. A review of natural products with antileishmanial activity. Phytomedicine 2005; 12: 514535

7 Bozorgi M, Memariani Z, Mobli M, Salehi Surmaghi MH, Shams-Ardekani $M R$, Rahimi R. Five Pistacia species (P. vera, P. atlantica, P. terebinthus, $P$. khinjuk, and P. lentiscus): a review of their traditional uses, phytochemistry, and pharmacology. ScientificWorldJournal 2013; 15: 1-33

8 Mozaffarian V. Trees and shrubs of Iran. Tehran, Iran: Farhang Moaser; 2005

9 Hosseinzadeh H, Behravan E, Soleimani M. Antinociceptive and anti-inflammatory effects of Pistacia vera leaf extract in mice. Iran J Pharm Res 2011; 10: 821-828

10 Dedoussis GVZ, Kaliora AC, Psarras S, Chiou A, Mylona A, Papadapoulos NG, Andrikopoulos NK. Antiatherogenic effect of Pistacia lentiscus via 
GSH restoration and down regulation of CD36 mRNA expression. Atherosclerosis 2004; 174: 293-303

11 Hamdan II, Afifi FU. Studies on the in vitro and in vivo hypoglycemic activities of some medicinal plants used in treatment of diabetes in Jordanian traditional medicine. J Ethnopharmacol 2004; 93: 117-121

12 Orhan I, Aslan M, Sener B, Kaiser M, Tasdemir D. In-vitro antiprotozoal activity of the lipophilic extracts of different parts of Turkish Pistacia vera L. Phytomedicine 2006; 13: 735-739

13 Ozçelik B, Aslan M, Orhan I, Karaoglu T. Antibacterial, antifungal, and antiviral activities of the lipophylic extracts of Pistacia vera. Microbiol Res 2005; 160: 159-164

14 Tsokou A, Georgopoulou K, Melliou E, Magiatis P, Tsitsa E. Composition and enantiomeric analysis of the essential oil of the fruits and the leaves of Pistacia vera from Greece. Molecules 2007; 12: 1233-1239

15 Alma MH, Nitz S, Kollmannsberger H, Digrak M, Efe FT, Yilmaz N. Chemical composition and antimicrobial activity of the essential oils from the gum of Turkish pistachio (Pistacia vera L.). J Agric Food Chem 2004; 52: 3911-3914

16 Cosa P, Vlietinck AJ, Berghe DV, Mae L. Anti-infective potential of natural products: how to develop a stronger in vitro 'proof-of-concept'. J Ethnopharmacol 2006; 106: 290-302

17 Cowan MM. Plant products as antimicrobial agents. Clin Microbiol Rev 1992; 12: 564-582

18 McCutcheon AR, Ellis SM, Hancock REW, Tower GNH. Antibiotic screening of medicinal plants of the British Columbian native peoples. J Ethnopharmacol 1992; 37: 213-223

19 de Melo JO, Bitencourt TA, Fachin AL, Cruz EM, de Jesus HC, Alves PB. Antidermatophytic and antileishmanial activities of essential oils from Lippia gracilis Schauer genotypes. Acta Trop 2013; 128: 110-115

20 Pearson RA, Manian A, Hall D, Harcus JL, Hewlett L. Antileishmanial activity of chlorpromazine. Antimicrob Agents Chemother 1984; 25 : 571-574

21 Mahmoudvand H, Sepahvand A, Jahanbakhsh S, Ezatpour B, Ayatollahi Mousavi SA. Evaluation of antifungal activities of the essential oil and various extracts of Nigella sativa and its main component, thymoquinone against pathogenic dermatophyte strains. J Mycol Med 2014; 24: $155-161$

22 Monzote L, García M, Pastor J, Gil L, Scull R, Maes L, Cos P, Gille L. Essential oil from Chenopodium ambrosioides and main components: activity against Leishmania, their mitochondria and other microorganisms. Exp Parasitol 2014; 136: 20-26
23 Sikkema J, De Bont DA, Poolman B. Mechanisms of membrane toxicity of hydrocarbons. Microbiol Mol Biol Rev 1995; 59: 201-222

24 Mahmoudvand H, Kheirandish F, Ghasemi Kia M, Tavakoli Kareshk A, Yarahmadi $M$. Chemical composition, protoscolicidal effects and acute toxicity of Pistacia atlantica Desf. fruit extract. Nat Prod Res 2015; 7: 14

25 Cristani M, D'Arrigo M, Mandalari G, Castelli F, Sarpietro MG, Micieli D, Venuti V, Bisignano G, Saija A, Trombetta D. Interaction of four monoterpenes contained in essential oils with model membranes: implications for their antibacterial activity. J Agric Food Chem 2007; 55: 6300-6308

26 Weniger B, Robledo S, Arango GJ, Deharo E, Arango R, Munoz V. Antiprotozoal activities of Colombian plants. J Ethnopharmacol 2001; 78: $193-$ 200

27 Mahmoudvand H, Ezzatkhah F, Sharififar F, Sharifi I, Dezaki ES. Antileishmanial and cytotoxic effects of essential oil and methanol extract of Myrtus communis L. Korean J Parasitol 2015; 53: 21-27

28 Adams RP. Identification of essential oil components by gas chromatography/mass spectroscopy. Carol Stream, IL: Allured Publishing Corporation; 2004

29 Mahmoudvand H, Tavakoli R, Sharififar F, Minaie K, Ezatpour B, Jahanbakhsh S, Sharifi I. Leishmanicidal and cytotoxic activities of Nigella sativa and its active principle, thymoquinone. Pharm Biol 2014; 4: 1-6

30 Ezatpour B, Saedi Dezaki E, Mahmoudvand H, Azadpour M, Ezzatkhah F. In vitro and in vivo antileishmanial effects of Pistacia khinjuk against Leishmania tropica and Leishmania major. Evid Based Complement Alternat Med 2015; 2015: 149707

31 Mahmoudvand H, Sharififar F, Sharifi I, Ezatpour B, Fasihi Harandi M, Makki MS, Jahanbakhsh S. In vitro inhibitory effect of Berberis vulgaris (Berberidaceae) and its main component, berberine against different Leishmania species. Iran J Parasitol 2014; 9: 28-36

32 OECD Guidelines for the Testing of Chemicals. Repeated Dose Dermal Toxicity: 21/28-day Study. OECD Guidelines for the Testing of Chemicals 1981; 410: $1-8$

33 Salehabadi AR, Karamian M, Motevalli Haghi F, Namaei MH. Effect of root bark extract of Berberis vulgaris L. on Leishmania major on BALB/ c mice. Parasitol Res 2014; 113: 953-957

34 Taran M, Mohebali M, Esmaeli J. In vivo efficacy of gum obtained Pistacia atlantica in experimental treatment of cutaneous leishmaniasis. Iran J Public Health 2010; 39: 36-41 